\title{
FRAMING PEACE: AN IDEOLOGICAL DISCOURSE ANALYSIS OF OBAMA'S SPEECH IN CAIRO
}

\author{
Semino and Edi Pujo Basuki \\ University of Nahdlatul Ulama Surabaya \\ e-mail:semino@unusa.ac.id
}

\begin{abstract}
Language is not always neutrally utilized by a politician. It is framed to persuade people to think and act in line with the intention of the orator or the ideology of the group he represents. This study dealt with ideological discourse analysis of Obama speech in Cairo. It focused on the cognitive processes showing the link of the ideology structure and discourse structures. This study was (1) to identify the underpinning ideology of the speech, (2) how the ideology structure link with the discourse structures employed, covering (a) how the ideology was expressed at global meaning level and at local meaning level, (b) how propositional structures were employed as ideology controlled strategy, (c) how sentence syntax was employed as ideology -controlled strategy, (d) how discourse forms or genres were employed as an ideology-controlled strategy, and (e) how styles were employed as persuasive ideology-controlled strategy in his efforts to frame peace. The framework of the research was Critical Discourse Analysis in general and Ideological Discourse Analysis in particular. So Ideological Discourse Analysis in this study was employed as Theory and Method. The data were the text of Obama's speech in Cairo 2009. The data in the form of quotes were analyzed, and interpreted by employing Critical Discourse Analysis (Fairclough, 1995) to uncover the underpinning ideology of the speech, and Ideological Discourse Analysis to show the link of the ideology structure and the discourse structures employed in the speech. The results were in the form of the description of the cognitive processes showing how the underpinning ideology was expressed at different levels of discourse structures for the purpose of framing peace.
\end{abstract}

Keywords: speech, ideology structure, discourse structure, ideological discourse analysis, ideological strategies

\section{INTRODUCTION}

Political speech is a political discourse in which language is not always utilized neutrally. Political discourse is framed to influence target communities to think and act in line with the intention of the orator, especially the view or ideology of the group he represents. Critical discourse analysis is needed to understand the true agenda of the orator, because "words [discourse] are never neutral" (Fiske, 1994), and "ideologies reside in texts" (Fairclough, 1995).

Obama's speech in Cairo is a strategic discourse. This speech can be regarded as a strategic discourse in a critical situation because Obama came to Cairo and spoke directly to Muslim communities when the tension between the West and the Muslim world was getting worse. This speech was intended to die down the tension between the two worlds with very different ideologies and a relatively long history of conflicts, in line with the mission of Obama's speech, "I have come here to seek a new beginning”. This critical and strategic role of the speech certainly required and employed a high level of sophistication of discourse structures.

According to van Dijk (2000) ideology exists in cognition, society and discourse. Ideology is a set of shared fundamental beliefs of a group or its members. The social dimension of ideology explains what kinds of groups and relations be- 
tween groups or institutions are involved in the development and reproduction of ideologies. The discursive dimension of ideologies explains how ideologies influence our daily texts and talk, how we understand ideological discourse, and how discourse is involved in the reproduction of ideology in society. In this discursive dimension is the focus of this study.

This study investigated the ideological discourses of Obama's speech in Cairo dated June 4, 2009 to uncover the cognitive processes showing the link between the ideology structure and the discourse structures employed in Obama's speech in Cairo. The focus of this study was on the cognitive processes of ideological discourse limited to some levels of discourse structures: meanings, propositional structure, sentence structure (syntax), discourse forms, and styles used for the purpose of framing a peace mission.

This study used Critical Discourse Analysis and van Dijk's framework of ideology and discourse structures not only to identify the underpinning ideology of the speech but also especially to reveal how the ideology affects the framing or choices of the discourse structures employed in the speech.

Specifically, the objectives of this study were (1) to identify the underpinning ideology of the speech, (2) to describe how the ideology structure was linked to the discourse structures employed in the speech, covering (a) how the ideology was expressed in the discourse meanings at both global and local levels, (b) how the propositional structures were employed as an ideologically-controlled strategy, (c) how the syntax were employed as an ideologically-controlled strategy, (d) how the discourse forms were utilized as an ideologically-controlled strategy, (e) and how styles were utilized as a persuasive ideologically-controlled strategy.

\section{REVIEW OF RELATED LITERATURE}

The theories employed in this study were those related to cognitive pragmatics and those related to concepts of ideology and discourse structures, and theoretical framework of Critical Discourse Analysis especially Ideological Discourse Analysis. Critical Discourse Analysis to uncover the hidden ideology and how the ideology was expressed in the discourse structures, and whereas Ideological Discourse Analysis Theory to be employed as a theoretical framework to reveal and describe how the employed discourse structures were linked with the ideology structure. The theoretical framework of Ideological Discourse Analysis employed in this study can be seen at Figure 1.

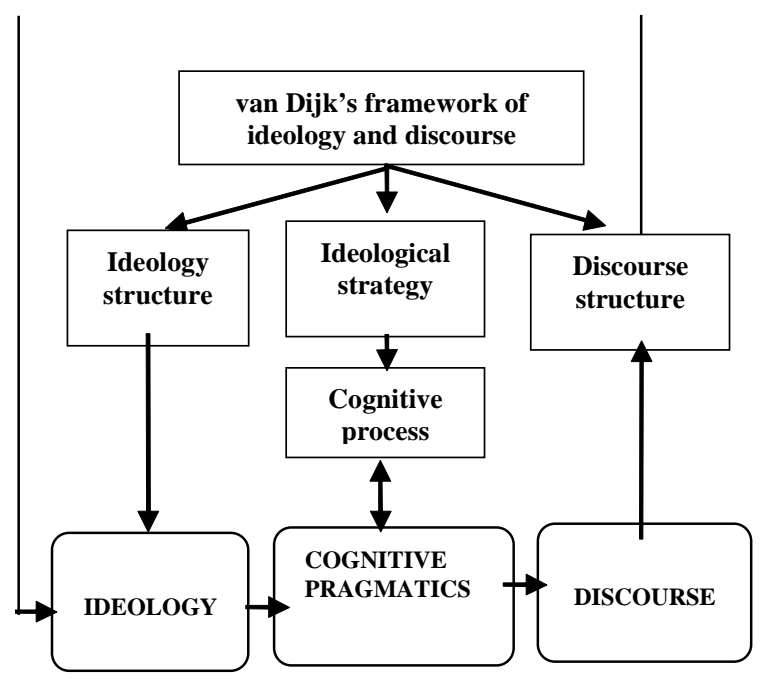

Figure 1: Theoretical framework of Ideological Discourse Analysis

Cognitive pragmatics is very relevant to reveal and describe the cognitive processes of discourse structures employed in the speech The pragmatic notions that play a significant role in discourse analysis related to meanings involve inference, implication, implicature, presupposition, coherence, and propositional construct. All these are cognitive processes of which each mechanism is observed and described, 
showing how ideology affects the choices of discourse structures.

The fact that listeners always use inferences may be utilized by an orator to gain high effectiveness and efficiency of the speech". A presupposition [caught by listeners through inference making] is something the speaker assumes to be the case prior to making an utterance" (Yule, 1996). Regarding ideology, presuppositions may be utilized to convey biased ideological propositions, such as to construct an implicature or a desired unuttered message to accomplish the goal of the speaker.

Coherence is an important element in the speech. Coherence indicates how meanings of sentences relate to each other or the relation of one proposition to another proposition. Coherence may be global or local. A discourse (or discourse fragment) is globally coherent if it has a topic. A sequence of propositions is locally coherent if it is about a sequence of actions, events, or situations that are mutually related by relations of causality or enablement (van Dijk, 2000). In a speech a global coherence frames a strategic schematic structure, and the details will follow that schema. It means a global coherence is open to ideological bias because a topic framing is of the orator's choice. So is a local coherence because it is also of the orator's choice affected by the orator's "mental model" that is inevitably influenced by ideology of the group he belongs to.

Related to the concepts of ideology and discourse, the notion of ideology used in this study refers to van Dijk's concept of ideology, covering ideology structure, ideology and discourse interface, ideological strategies, and discourse structures. According to van Dijk (2000), ideology is as the basis of social practices and expressed in discourse, and his concept can be partly summarized as follows: a. Ideologies are systems of beliefs shared by members of a social group.

b. Social groups also share other beliefs such as knowledge and attitudes.

c. The entire beliefs shared by a group are called social representations (SRs),

d. Ideologies are the basic organizing beliefs of SRs.

e. Groups also share other more general knowledge called "cultural common ground" as the foundation of all cognition between and across different groups, and thus is also presupposed by different ideologies.

f. Common ground may be empirically assessed as all beliefs that are presupposed in public discourse.

g. Part of the common ground are also general norms and values that are shared by a culture, and that some can be selected and organized in the groups' ideologies such as freedom, equality, justice or objectivity.

h. Ideology has a structure related to the basic social properties of a group such as (i) the criteria for membership, (ii) typical activities, (iii) the main aim, (iv) the norms and values, (v) the position which shows the pattern of relationships with other groups, and (vi) specific resources. This structure is called the structure of ideology.

Between social beliefs (ideology) and discourse is a cognitive interface that shows beliefs, opinions or personal experiences. This cognitive interface is a personal representation but also open to the influence of ideology. Such concept of cognitive interface is congruent with the concept of mental model (John - Laird, 1983; van Dijk \& Kintch, 1983; van Oostendorp \& Goldman, 1999). These models are personal representations (what is called episodic memory) of specific events people witness, participate in, hear or read about. "Such personal representations not only feature personal knowledge about such an event but also opinion" (van Dijk, 1983). That is, they are at the same time personal interpretation and evaluation of an event, and thus represents what we usually call "experience", whereas "[much] of the content of these models derives from [..] social beliefs, 
including ideologies." "[P]ersonal models can be [socially] biased, [thus also ideologically biased]" (van Dijk \& Kintsch, 1983).

The overall Ideological discourse strategies - used to enable the analysis of ideological discourse including those with more complex discourse structures - are formulated as follows: (van Dijk, 2000)

Emphasize the positive things about US. Emphasize the negative things about THEM.

De-emphasize the negative things about US.

De-emphasize the positive things about THEM.

The concept of this strategy is called "ideological square".

Discourse structures in this study is the most prominent element in which ideology is expressed. The discourse structures include several levels, covering (a) meanings of both global and local that may be exploited through lexicalization, coherence framing, and description level manipulation, (b) propositional structures that may be used to manipulate the predicate and actor, (c) sentence structure/syntax that may be utilized through manipulation of sentence or phrase structures, (d) discourse genre/text structure and (e) styles that may be utilized to make a convincing and impressive speech.

\section{METHOD}

This study used Critical Discourse Analysis (Fairclough, 1995) to uncover the ideology of Obama's Cairo speech, and van Dijk's framework of ideology and discourse structures or the theoretical framework of Ideological Discourse Analysis to systematically link the ideological structure to the discourse structures used in Obama's Cairo speech. The basic research design is as follows.

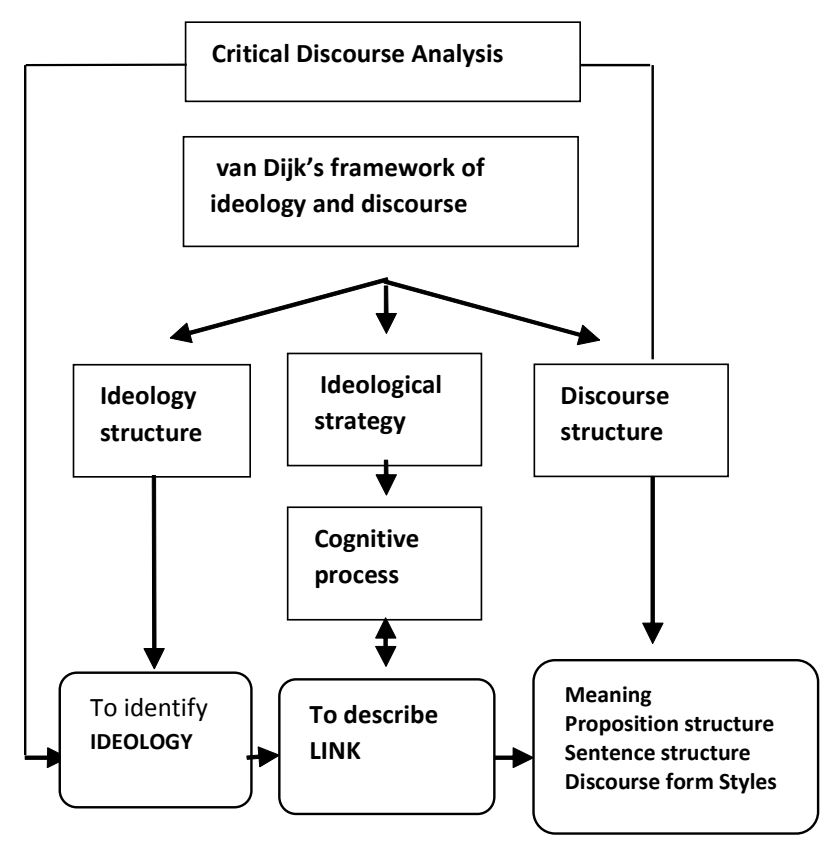

Figure 2: Basic Research Design

The approach of this research is descriptive qualitative. Therefore, it is fundamentally interpretive. That is, the researcher serves as a research instrument that makes interpretation of the text of the speech, the object of the research. Precisely, the framework of this study is Critical Discourse Analysis in general and Ideological Discourse Analysis in particular, that is, "integrating analysis of text, analysis of processes of text production [ ], and analysis of socio - cultural analysis of discursive event [in this case, the political speech of U.S. President]" (Fairclough, 1995).

The data sources were the text of Obama's speech in Cairo on June 4 of 2009 which lasted 58 minutes, 40 seconds and the text of Obama's Inauguration Speech of 2009 as supporting data. The data collected, selected, and used in this study were in the form of textual data. The techniques of data collection included (1) preparation of the text or transcript of Obama's Cairo speech of 2009 and the text of Obama Inauguration Speech 2009 as supporting data, and (2) check the validity of the data by com- 
paring the text to the Cairo speech video (as triangulation to ensure credibility of the data).

The data analysis included (1) reading the text closely and repeatedly, (2) recording quotes from the speech text related to the efforts intended to frame peace in line with the mission of the speech, (3) classifying the data into five categories under the headings of (a) meaning with sub-categories: global meaning and local meaning, (b) propositional structures with subcategories: predicate and actors, (c) sentence syntax with sub-categories: word -order and nominalization, (d) discourse genre with subcategories: narrative and argumentative, and (e) styles with sub-categories: metaphor and repetition, (4) coding the data for display, (5) interpreting the data, and (6) formulating a description of the findings for each sub-topic or focus of the research.

\section{RESULTS AND DISCUSSION}

An analytically explicit study needs to specify exactly what expressions or meanings of discourse give rise to what kind of inferences or other mental steps (cognitive processes). (van Dijk, 2000)

\section{(1) Ideology}

Obama constantly emphasized the importance of freedom, including religious freedom, freedom of expression, and freedom for choices to live as important values, as he expressed in his speech.

Freedom in America is indivisible from the freedom to practice one's religion.

[...] my commitment [however] to the government that reflects the will of its people.

I do have an unyielding belief that all people yearn for certain things: the ability speak their mind and have a say in how you are governed by the government, [and] the freedom to live as you choose.

Obama's ideology is liberalism because he indirectly reveals that liberalism is something of high value. As he said in the speech,

avoid [] dictating what clothes a Muslim woman should wear. We can not disguise hostility toward any religion behind the pretense of liberalism .

The ideology structure of liberalism has membership device of those who care for freedom. The typical activities include struggles for human rights, women's education, and religious tolerance. The ultimate aim is to make people become liberal, free and pro-choice, while the specific objective in this speech is "to seek a new beginning" which means a new world as Obama or liberal people want. The main values spreaded by liberalism are democratic values, freedom of expression, and equality through their resources of communication media in a variety of forms. Its position is against conservatism and fanaticism as expressed repeatedly in his speech.

(2) The link of the ideology structure and discourse structures employed in the Obama's Cairo Speech

Cognitive processes through which discourse structures were constructed were controlled by ideological discourse strategy, the structure of ideology and the mission of the Obama's Cairo Speech.

At global meaning level, topicalization was used to benefit the in-group by building a global coherence and lexicalization which frame a positive image of the West and a negatif image of Muslim extremists. The following is how Obama built the global coherence of the topic and purpose, background, and how global co- 
herence of the sub-topic on important issues were constructed.

I have come here to seek a new beginning between the United States and Muslims around the world (1), one based upon mutual interest and respect (2), and one based upon the truth that America and Islam are not exclusive, and need not be in competition (3).

Sentence (1) has the structure of global meaning because the text above is the topic as well as the main message of the Cairo Speech. Obama chose the topic "to seek a new beginning" which frames the good will of America whose President came directly in the middle of a Muslim community to change the course of bad relations between the West and the Muslim world. The phrase "a new beginning" brings an implicature that Obama or the U.S. has worked hard to promote "peace" not "war". The choice of global meaning or topic "to seek a new beginning” emphasizes the positive self-representation of America. On the contrary, the fact that America attacked the Muslims in Afghanistan and Iraq was expected to be buried deep, forgotten, and pushed away by the global meaning "[America is] trying to seek a new beginning" which implicitly means "to make peace". With this topic, common people are naturally inclined to accept it as positive.

To strengthen this strategic topic, the phrase "a new beginning" is further defined with a strategic phrase (2) "the one based upon mutual interest and mutual respect". Such lexicalization emphasizes the good will of America, yet cognitively blocks any reasons for war or violence to be initiated by Muslim fighters. That people should benefit from and respect one another is human concern. The phrase (2) becomes "a frame of reference" for listeners or people to think, discuss, and act for a better future and better relations. On the contrary, cognitively it blocks any opposite initiative to commit violence against people [implicitly means the West people], since those phrases (2) are common principles, and therefore it is cognitively and morally unrejectable.

With embedded clause (3), it is asserted that "America and Islam are not exclusive and need not be in competition," Americans want to end the war or violence. This phrase not only emphasizes the goodwill of America, but also de-emphasizes [in the mind of the listener] the fact of the brutal actions or destruction, as well as the hostility that America did.

We meet at a time of tension between the United
States and Muslims around the world - tension
rooted in historical forces that go beyond any
current policy debate. [ ] More recent, the ten-
sion has been fed by colonialism (1) that denied
rights and opportunities to many Muslim, and a
Cold War (2) in the which Muslim-majority coun-
tries were too often treated as proxies without
regard to their own aspiration. Moreover, the
sweeping change brought by modernity and glo-
balization (3) led many Muslims to view the West
as hostile to the traditions of Islam.

With the above paragraph, Obama built global coherence controlling the entire details of discourse of Cairo Speech. As the schematic structure, Obama built the background that the tension between America [representing the West] and Muslims around the world continued to increase, and the tension got worse due to "colonialism", "cold war", and "modernization and globalization". Such lexicalization or labeling of the causes of the tension positively frame Obama's empathy with the Muslim world because America recognizes that the victims of colonialism (1), Cold War (2) modernization and globalization were Muslims such as deprived of rights and opportunities, neglected aspirations, and disturbed tradition.

However, on this background, another cause of the tension is described in a separate 
paragraph telling people that the tension between the West and the Muslim world got worse and worse was due to Muslim extremists.

Violent extremists have exploited these tensions in a small but potent minority of Muslims. [ ] This has bred more fear and mistrust.

With that statement, Obama explicitly pointed out that the actors causing the tension were Muslim fighters. Even to emphasize the negative image of Muslim fighters, lexicalization is utilized to build a negative attribute with the phrase "violent extremists" with negative details, whereas for the other causes, they are only expressed through nominalization such as "colonialism", "Cold War", "modernity", and "globalization". The [West] actors are concealed. In that way a global coherence is built for the interest of America. Such global meaning tells us that [as if] the [only] cause of the escalation of the tension was the act of Muslim extremists, and to end this tension for a new beginning, the cause of the tension [referring to Muslim extremists] must be eliminated. And this cognitively leads to the first issue as a very strategic sub-topic of the speech that is, combating Muslim extremists.

On the first major issue - congruent with global coherence schema - dealing with the factor contributing the escalation of the conflict, Obama said,

"The first issue that we have to confront is violent extremism in all its forms.

Global coherence at the level of this subtopic frames a positive image of America being "fair", the word "extremism" is selected instead of "[Muslim] extremists", but the target is the Muslim extremists. At the detail level Obama only refers to Muslim brutality, the brutality of his own group is not explicitly expressed even throughout the Cairo Speech. Under this first sub-topic Muslims are framed negatively, whereas America remains positively framed.

On the second issue - the second major source of tension, that is, the situation between Israel and Palestina - Obama builds global coherence that leads the audience to empathize with Israel rather. In this sub-topic, Obama mentioned three parties involved in conflict, positioning as if Israel was alone against both Palestinians and the Arab world. One against two. Here is the line.

The second major source of tension [ ] is the situation between Israelis, Palestinians and the Arab world.

Obama also utilized the power of word lexicalization. "Israelis" means the people of Israel and the "Palestinians" means the people of Palestine. They are not states, so they look balanced. In fact Palestinians still fight for his country that is not yet recognized [by the West], while Israel is a state that has been recognized, so Israel struggles to expand its territory. Such lexicalization at the macro structure level is strongly ideologically biased.

On the third issue on nuclear, Obama framed this sub-topic in more general level, not merely about Iran with the following topic sentence.

The third source of tension is our shared interest in the rights and responsibilities of nations on nuclear weapons.

However, the target "fish" to catch was just Iran. Obama was telling the world to see the nuclear potential in the hands of Muslims, Iran, as stated in the next paragraph with this topic sentence.

This issue has been a source of tension between the U.S. and the Islamic Republic of Iran. 
It means this issue is about source of tension between the West and the Muslims. The global coherence on this issue is very neutral, but the details of this discourse focus only on Iran's nuclear. The nuclear in the hands of other countries particularly the West such as Israel and America who are de facto the enemies of Iran is not discussed even mentioned in the speech as if there were no nuclear weapons in their hands. Congruent with schematic coherence of the speech, this sub-topic negatively frames Muslim group [Iran] as a potential nuclear threat, but blurs the potential nuclear threat of Israel, and America is constantly framed as the hero of the world preventing the world from going into a dangerous path.

On the fourth issue related to the controversy of democracy in Iraq, Obama framed the fourth sub-topic as if the West never forced democracy on other nations [but the history told the opposite]. Here is his line.

Let me be clear: no system of government can or should be imposed on one nation by any other.

But, he did not stop there, with the global meaning or topic sentence of the next paragraph, Obama remained committed to supporting countries that reflect the democratic values reflecting the will of its people.

That does not lessen my commitment, however, to Governments that reflect the will of the people.

The values respecting "the will of the people" are the essence of democratic values. In other words, the term democracy is not forced, but the values of democracy should not be rejected. This sub-topic global meaning frames American as a hero defending the human freedom.

On the fifth issue on religious freedom, in addition to framing the goodwill of America, Obama not only framed discourse of anti-war triggered by religious disagreement in line with the mission of speech, but also promoted the values of liberty, especially "religious freedom", one of the ideological values of liberalism.

Under the sub-topic of religious freedom, in the next paragraph, Obama specifically framed negative discourse of religious problems among Muslims only.

Among Muslims, there is a disturbing tendency to measure one's own faith by the rejection of another's.

The essence of the message tells us that Muslims do not respect religious freedom. In fact they blame one another regarding their faiths. This discourse positively frames America who cares for peace, but the examples or facts used for that positive topic, Obama emphasized the negative side of Muslims, that is, hostility among fellow Muslims.

On the sixth issue on women's rights, Obama builds global meaning that women's rights to equality and freedom to live as they choose. Obama talked about equality,

Now let me be clear: issues of women's equality are by no means simply an issue for Islam.

On freedom to make a choice he said,

I do not believe that women must make the same choices as men in order to be equal, and I respect those women who choose to live their lives in traditional roles. But it should be their choice.

This discourse builds an implication that the practice of tradition regarding the roles of Muslim women have to be accepted but first screened by the Western ideology value of "freedom to make a choice", otherwise it is considered a violation to the "women's rights and equality". Such topicalization encourages the spreading of the values of American ideology, on the contrary, does not support the practice of the Muslim tradition by force. Again, this discourse frames America as a "hero", but 
frames the negative side of the consistent practice of the Muslim tradition in the eyes of both Muslim women and non- Muslims.

On the seventh issue on economic development and opportunities for Muslims, Obama built global coherence heavily loaded with ideological bias. Obama said,

The issues [... ] will not be easy to address. But, we have a responsibility to join together on behalf of the world we seek - a world where extremists no longer threaten our people.

America will help Muslim communities for the economic development and opportunity, but it is conditional. Under the sub-topic of the seventh issue, Obama identified what is needed and what must be done together between Western and Muslim communities to achieve a better future. Firstly, we need not blame globalization and modernization, as he put it, "there need not be contradiction between tradition and development." Secondly, the provision of educational opportunities through scholarship programs, "economic development through the creation of business networks", and "a new fund for the technological development in Muslim societies" are highlighted [urgent]. This discourse frames American, again, as a hero trying to help Muslim communities. But it is a promise and will only be realized under only one condition that shall be met first by the Muslim communities. The condition is that they must join forces to fight the [Muslims] extremists in order to create a world without extremists. The coherence is constructed so that it creates a global meaning that "development and economic opportunity is difficult to achieve because of the violence committed by Muslim extremists.

In the conclusive paragraph, here is Obama's statement.

All of us share this world for but a brief moment in time. The question is whether we spend that time focused on what pushes us apart (1), or whether we commit ourselves to an effort - a sustained effort - to find common ground, to focus on the future we seek for our children, and to respect the dignity of all human beings (2).

This conclusive discourse suggests focusing on the future to seek a "good" world and forget the "bad" past. This will lead audience to positive thinking, and leave the past full of destruction and humiliation in Muslim countries invaded by America. The future can be framed positively, but the bad past cannot be changed, therefore has to be forgotten, washed from audience's mind. The sentence "The question is whether we spend that time focused on what pushes us apart" is the positive paraphrasing of focusing on the bad past or very destructive wars of America in Middle East, and used to hide or de-emphasize the negative war image of America. The sentence "or whether we commit ourselves to [] a sustained effort to find common ground, to focus on the future we seek for our children, and to respect the dignity of all human beings" is used to frame America's intention positively and at the same time cognitively to direct audience to avoid conflicting ideas or attitudes (to find common ground) and to focus on desired state of affair only that can be framed as wanted and to "respect the dignity of all human being", something morally unrejectable and undebatable. Then the choice naturally falls on the positive one.

At local meanings, the utilized cognitive processes include building implications, lexicalization, level of description/ degree of details, presuppositions, local coherence, illustration/ example, paraphrasing, and disclaimer.

Implications were built by Obama to obscure the bad side of the West group. The phrase "tension has been fed by colonialism that denied rights and opportunities to many 
Muslims and a Cold War" carry implicatures that the cause of tension is not [West] humans but something abstract without identified human actors with the labels like "colonialism" and "Cold War". Muslim victims of colonialism are however obscured by not using the word "victims" or "suffering Muslims", instead the phrase "that denied rights and opportunities to [ ] Muslims" is used. That phrase uses words that need interpretation. Negative actions of Israel are reduced to only a matter of settlement with the phrase "It is time for these settlements to stop". This sentence hides [Israel] actors and brings an implication as if there were no bloodshed caused by Israel.

Lexicalization was utilized by Obama to emphasize bad image of Muslim fighters, but also to build a positive image of America as well as to obscure the negative part of America. Obama employed extra explicit negative wording for what Muslim fighters do such as "They [Muslim fighters] have killed in many countries". The word "killed" is used to describe the act of Muslim fighters and is never used for identical acts committed by Israeli soldiers or American soldiers. On the contrary, Obama positioned himself as a rescuer of Iraq and framed the discourse as if Americans had never attacked Iraq with the following line.

America has a dual responsibility: to help Iraq forge a better future - and to leave Iraq to Iraqis.

The word "help" is employed to frame America as a "good person", but in reality America has devastated Iraq, and the phrase "leave Iraq to the Iraqis" is employed to frame America as a generous actor as if America were not an agresor or invader of Iraq.

Level of description or degree of detail was built by Obama to emphasize the negative things about Muslim fighters, on the contrary to obscure or even to completely conceal the negative things about the in-group. To emphasize "the brutality" of Muslim fighters, the following sentences are employed.

They have killed in many countries.

They have killed people of different faiths - more

than any other, they have killed Muslims.

The word "kill" is used with repetition, and the intensity is amplified by adding adverb "in many countries", further amplified with an object "people of different faiths", even more with "have killed Muslims". It implies their acts spread across countries like epidemic, violence is committed regardless of race and religion even among their Muslims ['own brothers'].

The local meanings under the second issue on an effort to address the situation of Israel and Palestine relation are framed so as to show Obama's empathy to both the Israelis and the Palestinians, but the framing is ideologically biased. The narrative about Jews [Israelis in the past], is made very detailed and extra explicit with phrases that evoke sympathy such as "being persecuted", “enslaved, "tortured", "shot”, "gassed to death", and " killed. The suffering of the people of Israel [in the past] is intensified by the number of the deaths of Israelis [in the past] as stated "Six million Jews were killed" and further made more unforgettable with the phrase "more than the entire Jewish population of Israel today". In short, the level of the description of the suffering of Israelis [in the past] is relatively very detailed and more explicit than that of the suffering of the Palestinian people.

Obama did not deny that the Palestinians were suffering, but he did not express it explicitly. Obama tended to use interpretive expressions like "have suffered in a pursuit of the homeland", "they endured the pain of dislocation", and "many 
waits in refugee camps" as if it was just a matter of residence, as if there were no killing of Palestinians by Israeli soldiers. By lowering the level of description and the degree of the details, Obama blured the level of the suffering of the Palestinians and the role of actors [Israel] of the negative actions. "They endured the daily humiliations [] that come with occupation" The word "humiliations" is chosen to replace the explicit words for the actual action instead of explicit words such as " they [the Palestinians] were attacked", "shot" from day to day, or " killed " in the way Obama described the suffering of the Jews. The word "occupation" is chosen so that the agent [Israel] are downgraded or unexposed in order to remain relevant to the global coherence of the second issue intended to frame discourse sympathetic to Israel.

Presupposition strategy was used by Obama to end the suffering related to Israeli - Palestinian relation. Obama framed discourse urging both parties to end the conflict with biased global meanings in the topic sentences.

Palestinians must abandon violence (1)

Israel must live up to its obligations to ensure

Palestina can live and work ... (2)

With sentence (1), it is presupposed that Palestinians have been commiting violence, and it is also implied as if Palestinas alone were brutal and therefore responsible for ongoing violence, Israel were not. Obama treated Israel differently for this matter. With sentence (2) that none of his words for Israel indicate violence as if Israel never did brutality against Palestinians. The choice of words for Israel tends to fall on interpretive words, instead of explicit words to describe Israel's violence such as "Israel must stop violence and settlement construction" or "stop shooting or killing Palestinian people".

Local coherence was built by Obama to frame Hamas' position as the troublemaker responsible for the social disorder experienced by Palestinians. Obama said,

To play a role in fulfilling Palestinian aspirations, and to unify the Palestinian people, Hamas must put an end to violence, recognize past agreements, and recognize Israel 's right to exist.

It is implied that Hamas is the only cause of the unfulfilled aspirations and failure in unifying Palestinians, whereas Israel's brutality contribution is not mentioned. Hamas is framed as the party responsible for the realization of the unity of Palestinians, but the fact is that the unity or state of Palestine is not wanted by Israel. Even Westerners tend to divide Muslims into groups of Muslim with tolerance and Muslim extremists. The local coherence built is manipulative. All the local coherence constructs regarding Israeli-Palestinian relations are intended to obscure the negative side of Israel, on contrary, to put Hamas as the party to blame, the one ignoring other rights [Israel's "rights"].

Illustration or example was used by Obama with explicit words and high degree of details to frame the negative things of Muslim groups, but not for Israel. Obama said,

But let us be clear: al Qaeda killed nearly 3,000 people on that day. The Victims were innocent men, women and children from America and many other nations who had done nothing to harm anybody. And yet Al Qaeda chose to ruthlessly murder these people, claimed credit for the attack, and even now states their determination to kill on a massive scale. They have affiliates in many countries and are trying to expand their reach.

Obama used the foresaid illustration to support his opinion that al Qaeda deserved to be punished. Obama used the figures to show the intolerable number of 3,000 people killed. Obama emphasized it with the choice of words "children" and "women" who are "innocent", not "the American people" so that they are 
framed as "enemies of humanity". This example is made to emphasize the escalating brutality of [Muslim] extremists with the phrase "[the victim] from many other countries, with the word "ruthlessly", the phrase "determined to kill on a massive scale" and to lock it with the statement "This is not opinions to be debated, but the fact that must be addressed".

Disclaimer was by Obama to conceal or to obscure or to eliminate the negative side of the in-group. Regarding the occupation over the Middle East, Obama said,

We do not want to keep our troops in Afghanistan. We seek no military bases there [] we would gladly bring every single one of our troops home if we could be confident there were not violent extremists in Afghanistan and Pakistan determined to kill as many Americans as they possibly can.

With the disclaimer that "we do not want to continue to put our troops in Afghanistan" Obama built implication that America is not "greedy" but the fact is that American troops are still operating there. With the phrase "We would gladly bring every single one of our troops home if we could be confident there were no extremists in Afghanistan and Pakistan determined to kill as many Americans as possible" implies that American soldiers still remain in and occupy the country.

\section{Propositional Structure}

Obama employed 24 sentences with propositional structures with positive predicates for the agents of the in-group. Out of all the positive predicates, more than $75 \%$ are promises. To emphasize the negative side of the outgroups, Obama used 15 sentences with propositional structures containing negative predicates such as those in the form of explicit verbs, such as "kill", "murder" and negative attributes used to emphasize the Muslims' bru- tality. To obscure the bad side of the in-group, Obama used the 10 sentences with propositional structures containing softened negative predicates such as "Israel must live up its responsibilities".

Another important property of a proposition is an argument or an actor. The treatment to the position of an actor is controlled by ideology. Obama used 13 sentences with propositional structures positioning the actor of the in-group as the agent of the posivitive predicates. However, America is as a positive agent of $75 \%$ of promised positive actions.

There are 15 sentences containing propositional structures with the actors positioned to emphasize the negative side of the out-group [Muslim groups]. Al Qaeda, Hamas, Palestinians, or Iran is tropicalized as the agent of a negative predicate. The highest frequency of negative predicate use is "kill", $40 \%$ of the total destructive action verbs.

To obscure the negative side of the ingroup, Obama employed 7 sentences containing propositional structures of high level of sophistication. For example, "the continuing humanitarian crisis in Gaza does not serve Israel's "security". The agent in one atomic proposition unit is made implicit, because the agent is Israel, America's friend. The level of its sophistication gets higher when the predicate and object "does not serve Israel's security" is added to the sentence subject. Israel in this sentence is positioned as the object. Such construct puts Israel as the victim. Such sophisticated proposition structure is controlled by ideology to ensure Israel does not seem negative as if Israel were a party in need for help not an agresor.

\section{Sentence Syntax}

To emphasize the positive image of America, Obama employed 24 sentences using the 
active form to tropicalize Obama or America as a "good" agent of "good" action. For example, "fight against negative stereotypes of Islam". For all promised actions, Obama tropicalized himself as a generous person.

To emphasize the negative side of Muslim [fighters], Obama used active sentence with negative verbs to tropicalize Muslim groups as agent-actors. The negative verbs employed are destructive actions: "killed" and "murder".

To de-emphasize the negative side of the American group, Obama used passive sentences to downgrade or de-tropicalize or leave out the agent [of the in-group] when the predicate is a negative verb, for instance,

Muslim - majority countries were too often treated as proxies without regard to their own aspirations"

The actor whose role is as an agent is eliminated or downgraded.

\section{Discourse Form/Genre}

The choice of discourse forms is intended to support the effectiveness of the delivery of points raised in the speech. The dominant discourse forms used by Obama are "narrative" and "argumentative". Narrative is used to support the main message of Cairo Speech "a new beginning", the world where the West and the Muslim world can live together in peace.

Part of this conviction is rooted in my experience. I am a Christian, but my father from a Kenyan family that includes generations of Muslims. As a boy I spent several years in Indonesia and heard the call of the adzaan at the break of dawn and the fall of the dusk. As young man I worked in Chicago communities where many found dignity and peace in their Muslim faith.

The narrative above is a narrative of experience utilized as a premise for an argument supporting Obama's conviction that a peaceful life is not impossible.
Obama used argumentative to convince that Muslim extremists must be combated because they have killed innocent men, women and children, and to frame a theme that America is not at war with Islam but violent extremism. Here is one example.

In Ankara, I made clear that America is not - and never will be - at war with Islam. We will, however, relentlessly confront violent extremists who pose a grave threat to our security. Because we reject the same thing that people of all Faiths reject: the killing of innocent men, women, and children. And it is my first duty as President to protect the American people.

\section{Styles}

Metaphors was used by Obama to impress Muslim audience about Islamic civilization, to forget the bad past, to spread true democratic values, to convince the importance of education, and to choose the path of peace.

The beginning of the speech is about Islamic culture which has a major contribution to the world.

Islamic culture has given us majestic arches and souring spires.

Islamic culture has given great contribution to the advancement of human civilization including a tradition of tolerance. Obama tried to build good relation by mentioning good things about Islam but focus on relevant things: reminding Islam has made good progress and Islam has tradition of tolerance. Then an implication is built that the mission of the speech is in line with the mission of Islam, therefore it deserves great support from the Muslim world.

To eliminate the inhibiting factors that stand in the way of peace as a result of a bad experience and suffering of Muslims due to the aggression by the West, Obama tried to eliminate this part with a metaphor. 
So whatever we think of the past, we must not be prisoners of the past.

Obama asked Muslims to forget the past and to focus on the future, to forget the war and to focus on partnership, and to forget who we are to fight against and to focus on what we can build. That metaphor is used to lock the mission of the speech, for peace only.

To convince Muslims of the importance of education, Obama used another ideologically biased metaphor.

But all of us must recognize that education and innovation will be the currency of the $21^{\text {st }}$ century, and in too many Muslim communities there remains underinvestment in these areas.

With this metaphor, Obama tried to influence Muslims to forget their oil and pursue the education offered by Obama.

Relying on oil and gas belongs to the past as Obama said,

This is important because no development strategy can be based only upon what comes out of the ground, nor can it be sustained while young people are out of work.

What Obama was saying is that "forget your oil and gas, buy our education and innovation."

\section{CLONCLUSION}

The underlying ideology of Obama's Cairo speech is liberalism. The dominant elements of the ideology structure: the main aim of ideology, democratic values, typical activities, position in relation to other groups strongly affect choices of discourse structures in Obama's Cairo speech.

The link of the discourse structures and the ideology structure is proved strong as observed in (a) global meanings framed affectively through ideologically controlled topicalization involving processes of lexicalization, relevant schematic coherence framing; in local meanings framed through processes of lexicalization, description level framing, presupposition, coherence building, paraphrasing and disclaimer; (b) propositional structures effectively framed at various level of sophistication (c) sentence syntax effectively constructed (d) text structure appropriately selected (d) and styles effectively utilized

\section{REFREENCES}

Fairclough. 1995. Critical Discourse Analysis. London: Longman.

Fairclough, N. \& Wodak. 1997. Critical Discourse Analysis. In T.A. van Dijk (Ed.), Discourse as social interaction (pp. 258-284). London, England: Sage Publications.

Fiske, J. 1994. Media matters: Everyday culture and political change. Minneapolis: University of Minnesota Press.

Johnson-Laird. 1983. Mental Models: Towards a Cognitive Science of Language, Inference, and Consciousness. Cambridge: Cambridge University Press.

van Dijk. 1984. Prejudice in Discourse: An Analysis of Ethnic Prejudice Cognition and Conversation. Amsterdam: Benjamins.

van Dijk. 1995. Discourse Analysis as Ideology Analysis in Wenden.

van Dijk. 1995. Discourse Semantics and Ideology. London: Sage Publication.

van Dijk. 2000. Ideological Discourse Analysis. Rettriev March 15,2013, from http://www. discourses.org/OldArticles/Ideological\% 20discourse\%20analysis.pdf

van Oostendorp \& Goldman. 1999. The Construction of Mental Representations: Lawrence Erlbaum Associates, Incorporated.

Yule, G. 1996. Pragmatics. Oxford: Oxford University Press. 